\title{
Information Governance in the Big Data Era: Aligning Organizational Capabilities
}

\author{
Patrick Mikalef \\ Norwegian University of \\ Science and Technology \\ patrick.mikalef@ntnu.no
}

\author{
John Krogstie \\ Norwegian University of \\ Science and Technology \\ john.krogstie@ntnu.no
}

\author{
Rogier van de Wetering \\ Open Universiteit \\ rogier.vandewetering@ou.nl
}

\author{
Ilias O. Pappas \\ Norwegian University of Science and Technology \\ ilpappas@ntnu.no
}

\begin{abstract}
With big data growing rapidly in importance, academics and practitioners have been considering the means through which they can incorporate the shifts these technologies bring into their competitive strategies. Drawing on the emerging importance of information governance, this study examines the mechanisms through which it can facilitate competitive performance by aligning organizational capabilities. To test our proposed research model, we used survey data from 158 chief information officers and IT managers working in Norwegian firms. By means of partial least squares structural equation modeling (PLS-SEM), results show that information governance helps strengthen a firms' dynamic and operational capabilities, which in turn lead to competitive performance gains. The results are discussed in relation to their theoretical and practical implications.
\end{abstract}

\section{Introduction}

An increasing number of firms are accelerating the deployment of their big data analytics initiatives with the aim of developing critical insight that can ultimately provide them with a competitive advantage [1]. Necessitated by the rapidly expanding data volume, velocity, and variety, significant developments have been documented in terms of techniques and technologies for data storage, analysis, and visualization. Nevertheless, there is significantly less research on the governance of the information artifact that is associated with such investments in big data analytics, and a lack of understanding of the effects it has on performance. To date, most studies have emphasized on infrastructure, intelligence, and analytics tools, while other related resources such as human skills and knowledge have been largely

\author{
Michail N. Giannakos \\ Norwegian University of Science and Technology \\ michailg@ntnu.no
}

disregarded [2]. Exponential data growth has placed information governance as a critical issue for senior IT and business management [3].

The issue of IT governance has been at the center of attention for both IT researchers and practitioners for over two decades. Empirical evidence suggests that by establishing appropriate governance schemes and practices, the implementation of IT strategy can be executed in alignment with the business strategy, which ultimately leads to firm performance gains [4]. The effects of such governance mechanisms have been found to have an impact even at the strategic level of the firm [5]. Nevertheless, while most emphasis has been placed on the governance of the physical artifact, the rapid expansion of information through the hype of big data requires a close examination of the practice of information governance. While empirical research is still scarce, commentaries argue that establishing information governance practices within firms are likely to lead to competitive performance gains by enabling an improvement of existing modes of operation, while also facilitating strategic flexibility and adaptation of the firm to the external environment [6]. Information governance as such is regarded as a subset of IT governance and is defined as a collection of capabilities or practices for the creation, capture, valuation, storage, usage, control, access, archival, and deletion of information over its life cycle [6].

To examine the impact of information governance in contemporary organizations, we analyzed surveybased data from 158 firms that have embarked on big data initiatives. Building on the resource-based view and dynamic capabilities view of the firm, we argue that information governance helps strengthen a firms operational and dynamic capabilities, which ultimately lead to competitive performance. In effect, our research attempts to shed some light on the following research question: "What is the impact of information governance practices for firms that have engaged in 
big data initiatives?". In doing so, we also provide a measurement instrument of evaluating the maturity level of information governance practices within firms. The remainder of the paper is as follows. In the next section, we overview existing literature on information governance, organizational capabilities, and in sequence formulate our research hypotheses. We then present the methodology to actualize our quantitative research study, followed by the statistical analysis of the obtained data. We conclude by discussing the practical and theoretical implications of the study and drawing the limitations that can be overcome in future research.

\section{Conceptual Development}

\subsection{Information Governance}

Governance has been in the center of organizational literature for more than half a century. Similarly, in IS literature the notion of IT governance has long been regarded as a key success factor of any implementation [7]. IT governance has been defined as including the patterns of authority for key IT activities in business firms, including IT infrastructure, IT use, and project management [7]. The main premise developed by IS researchers and practitioners is that IT governance is directly associated to the implementation of IT strategy, and thereby is critical in overall business-IT alignment [4]. Nevertheless, while the dominant focus of IT governance literature has been on the IT artifact, with the advent of big data analytics a renewed interest has been placed on the structures and practices related to the information artifact [6]. As there are multiple facets related to the governance of IT, Weber and colleagues [8] suggest that information governance encompasses activities relating to decision-maker roles (structural practices), decision tasks (procedural practices), and person responsibilities and development (relational practices). While the vast majority of companies have established IT governance schemes to align their IT strategy with their business strategy, a very small percentage have made any significant efforts in establishing an information governance practice, despite the hype of big data analytics and its potential business value [9]. The main distinction between the two is that the former is a broader notion encompassing all activities relating to IT management, while the latter is centered on the data a firm owns, generates, or is leveraging. The focus of information governance as such is to harness the power of the continually growing data to extract information which ultimately will lead to better decision making. With the advent of big data, the role of governance over the data artifact is becoming increasingly more relevant. Yet, the issue of information governance is not only lagging in terms of practitioners' adoption. Studies to date have still to embark on the issue of examining the effects that adopting information governance mechanisms have on performance [10].

\subsection{Organizational Capabilities}

The competitive benefits that a firm currently has managed to obtain are a result of strengths built in reaction to environmental responsiveness strategies. These strengths can be explained in terms of organizational capabilities, i.e. processes that facilitate the most efficient, effective and competitive use of a firms' assets whether tangible or intangible [11]. In this perspective, capabilities represent the potential of a business to achieve certain objectives by means of focused deployment, and represent the building blocks on which firms compete in the market. Designing and constructing desired organizational capabilities is a procedure that unfolds over time, and reflects choices made in support to a firm's long-term competitive strategy. Organizational capabilities emerge through the strategic application and complex interactions of resources that a firms owns or is capable of controlling, and the most effective means of orchestrating and deploying them [12]. Following the definition of Winter [13], a capability can be described as a highlevel routine (or a collection of routines), with routines comprising of purposefully learned behaviors, highly patterned, repetitious or quasi-repetitious, founded in part in tacit knowledge. Past research in the domain of strategic management has made great strides to develop and refine different types of organizational capabilities. The general consensus is that capabilities operate quite differently, and result in varying levels of competitive advantage and firm performance based on a number of internal and external factors [14]. Based on the idea that firms must be both stable enough to continue to deliver value in their own distinctive way, and agile and adaptive enough to restructure their value proposition when circumstances demand it, there is a well-documented distinction between operational (ordinary) and dynamic capabilities.

In the resource based view (RBV), operational capabilities have been identified as an important source for the generation of sustainable competitive advantages [15]. Operational capabilities are those that allow a firm to make a living in the present. In incomplete markets, heterogeneity among firm resources and capabilities can serve as the basis for developing competitive advantages and rent differentials [16]. Nevertheless, conditions of high environmental uncertainty, market volatility, and frequent change, have raised questions regarding the 
rate to which operational capabilities erode and cease to provide competitive gains [17]. It is suggested that in such circumstances the focus should be shifted to strengthening capacities of change and re-adjustment of operational capabilities. The dynamic capabilities view has been put forth to answer this gap as a neoSchumpeterian theory of the firm [18]. The dynamic capabilities view repositions the focus on the renewal of existing organizational capabilities as a means of competitive survival for the firm [13]. The main differentiation between operational and dynamic capabilities is that the former allow firms to make a living in the present, while the latter enable their modification in response to the shifting external environment [13]. As such, they are particularly important for the competitive survival of firms in contemporary dynamic and quasi-globalized markets. Dynamic capabilities are suggested to deliver rents from new combinations of capabilities and assets, and produce outcomes that are capable of shaping the marketplace, such as entrepreneurship, innovation, and semi-continuous asset orchestration and business reconfiguration [19].

\subsection{The impact of Information Governance on Competitive Performance}

While research on the impact of information governance on competitive performance is still scarce, there have been some studies that embark on the quest of explaining the organizational effects that it may have $[6,20]$. Through a qualitative research approach, Tallon et al. [6] demonstrate that information governance has effects that are often reflected in the industry in which the firm operates. Specifically, in the health care industry the provisioning of information led to reduced medical errors and an overall increase in efficiency. In the airline industry, information governance was linked to enhanced decision making in scheduling, market analysis, and ticket pricing. Information governance however is an important element of delivering data-driven innovations. By coalescing data from different sources, insight can be generated that was previously unobtainable. Kathuria and colleagues [21] show that by developing a proficient mechanism of managing information-related artifacts, both incremental and radical innovations can emerge. Such effects of information governance can be detected in the healthcare sector where personalized medicine is being developed based on big data analytics of systems biology (e.g. genomics) with electronic health record data [22]. These types of initiatives require a strong information governance scheme that is able to establish the processes and practices for exploiting available data to the best possible extent. Consequently, the effect of information governance can be posited to be an influencer of both a firms' dynamic and operational capabilities. By delivering improvements in both existing modes of operations and setting the necessary conditions that facilitate the adaptive capability of a firm, information governance is posited as being an indirect antecedent of performance. Consequently, we hypothesize the following.

H1: Information governance has a positive effect on a firm's dynamic capabilities

H2: Information governance has a positive effect on a firm's operational capabilities

The insight derived from a big data analytics capability can in sequence influence a firms' competitive performance in multiple ways. By strengthening its dynamic capabilities there are several mechanisms which lead to business and competitive value. Literature has placed particular emphasis to the potential of dynamic capabilities to increase (a) innovativeness [23] and (b) responsiveness to match/address changing environments and improve effectiveness [17, 24]. First, dynamic capabilities can positively affect competitive performance by enabling a firm to identify and respond to opportunities, by developing new processes, products, and services [25]. Second, dynamic capabilities can improve the speed, effectiveness, and efficiency with which a firm operates and responds to changes in its environment developing as such, an organizational agility [26]. Nevertheless, operational capabilities have also been long-linked with competitive performance gains, even under the competing and complementary link with dynamic capabilities [27]. Effective operational capabilities are necessary for attaining and sustaining a competitive advantage. Marketing capabilities enable firms to better understand their customers' current and future needs and to be more capable of promptly serving these needs [28]. Marketing capabilities positively affect competitive performance by creating customer satisfaction and loyalty and superior market performance [29]. Technological capabilities create competitive value by allowing a firm to transform input into output in an efficient and effective way while being able to avoid excessive costs, time, organizational disruptions or performance losses [28]. Thus, we hypothesize the following:

H3: Dynamic capabilities have a significant positive effect on competitive performance

H4: Operational capabilities have a significant positive effect on competitive performance 
While dynamic capabilities may produce competitive performance gains on their own right, it is suggested in literature that one of their mechanisms of action is by enabling, or strengthening, existing operational capabilities [30]. This idea has been initiated by Eisenhardt's and Martin's [24] argument, that dynamic capabilities are necessary, but not sufficient conditions for competitive advantage. According to this perspective, competitive performance does not rely on dynamic capabilities per se, but rather, on the resource configurations created by dynamic capabilities. In this sense, dynamic capabilities are perceived as strategic options that allow firms to renew their existing operational capabilities when the opportunity or need arises [31]. Zahra et al. [32] supported this view proposing that dynamic capabilities impact competitive performance by facilitating changes in substantive capabilities. Protegerou et al. [28] also adopt this perspective, demonstrating that dynamic capabilities create value indirectly by changing operational capabilities. Following this line of thinking we hypothesize the following:

H5: Dynamic capabilities have a significant positive effect on a firms' operational capabilities

\section{Methods}

\subsection{Data}

In order to empirically test the previously formulated research hypotheses, a survey instrument was developed and administered to key informants within firms. Target respondents were high-level IT executives, since in the majority of cases, they are the most knowledgeable about the current state of technical and business aspects, such as those asked in the survey instrument. All constructs and their corresponding items were measured on a 7-point likert scale [33]. To examine the statistical properties and validity of the measures, a small-cycle study pre-test was conducted with 19 firms. The pre-testing procedure allowed us to determine the face and content validity of items and to make sure that key respondents would be capable of understanding the survey questions as intended. When the pre-test phase was over, respondents were contacted by phone and asked about the quality of the questions and were encouraged to provide suggestions to improve the clarity of the instrument.

As part of the main study, a population of 500 firms was utilized from a list of Norway's 500 largest companies, measured in terms of revenue (Kapital 500). Each of these firms was contacted through a phone call, in order to get contact details of the most appropriate key respondent (e.g. chief information officer, chief technology officer) and inform them about the aims and goals of the research. To make sure of a collective response, respondents were asked to consult other employees within their firms for information that they were not highly knowledgeable about and was requested in the survey. The data collection procedure lasted for approximately three months (February 2017 - April 2017), and the average completion time was 14 minutes. From a total of 189 firms that initiated the completion of the survey, 158 provided completed responses, which resulted in a valid response rate of $31.6 \%$. While this response rate is slightly higher than similar studies that use key informants, it can be explained by the personal communication that was established by phone with each of the potential respondents [34]. The survey was completed predominantly by chief information officers (CIOs), chief technology officers (CTOs) chief digital officers (CDOs), and IT managers. In accordance with the directive of the EU commission size-class classification (2003/361/EC), firms were separated into large $(62 \%)$, medium (19\%), small (18\%), and micro $(1 \%)$.

Table 1 Sample Characteristics

\begin{tabular}{|c|c|c|}
\hline & $\begin{array}{l}\text { Population } \\
\text { (n) }\end{array}$ & $\begin{array}{l}\text { Frequency } \\
(\%)\end{array}$ \\
\hline \multicolumn{3}{|l|}{ Industry } \\
\hline Bank \& Financials & 28 & $17.7 \%$ \\
\hline Consumer Goods & 16 & $10.1 \%$ \\
\hline $\begin{array}{l}\text { Industrials (Construction \& } \\
\text { Industrial goods) }\end{array}$ & 12 & $7.59 \%$ \\
\hline ICT and Telecommunications & 11 & $6.96 \%$ \\
\hline Oil \& Gas & 9 & $5.69 \%$ \\
\hline Technology & 9 & $5.69 \%$ \\
\hline Media & 9 & $5.69 \%$ \\
\hline Transport & 8 & $5.06 \%$ \\
\hline $\begin{array}{l}\text { Other (Shipping, Basic } \\
\text { Materials, Consumer Services } \\
\text { etc.) }\end{array}$ & 56 & $35.5 \%$ \\
\hline \multicolumn{3}{|l|}{$\begin{array}{l}\text { Total Big Data Analytics } \\
\text { Experience }\end{array}$} \\
\hline$<1$ year & 42 & $26.6 \%$ \\
\hline $1-2$ years & 38 & $24.1 \%$ \\
\hline $2-3$ years & 30 & $18.9 \%$ \\
\hline $3-4$ years & 21 & $13.3 \%$ \\
\hline $4+$ years & 27 & $17.1 \%$ \\
\hline \multicolumn{3}{|l|}{ Age of Company } \\
\hline$<1$ year & 0 & $0.0 \%$ \\
\hline $1-4$ years & 5 & $3.2 \%$ \\
\hline $5-9$ years & 9 & $5.7 \%$ \\
\hline
\end{tabular}


Since in large-scale studies such as the present nonresponse bias is common problem, measures were taken both during the collection of the data to make sure we had a representative response rate, as well as after the concluding of the data gathering. Respondents were given an incentive to take part in the study, and were provided with a personalized report which benchmarked their firms' performance in a number of functional areas compared to industry and country averages [35]. Considering that all data were collected from a single source and at one point in time, and that all data were perceptions of key respondents, we controlled for common method bias following the guidelines of Chang et al. [36]. Ex-ante, respondents were informed that all the information they provided would remain completely anonymous and confidential, and that any analysis of data would be done on an aggregate level and for research purposes only. Expost, Harman's single factor test was utilized, with outcomes indicating that a single construct could not account for the majority of variance [37].

\subsection{Variable Definition and Measurement}

Information Governance $(I G)$ is defined in line with the study of Tallon and colleagues [6] as a collection of capabilities or practices for the creation, capture, valuation, storage, usage, control, access, archival, and deletion of information over its life cycle. This definition clearly highlights the two main goals of information governance which are to maximize the potential value of information to the organization by ensuring data quality, and to protect information so that its value to the organization is not lost. Using the framework of Paterson [38], and building on related work on information governance [6], three pillars are identified and quantified. These include structural, procedural, and relational practices. As such, IG is conceptualized and developed as a second-order formative construct. The three underlying pillars that comprise a IG are formulated as first-order reflective constructs. Previous studies were utilized to identify and develop the measurement scale for each of the underlying dimensions $[6,8]$ and a pre-test with a number of experts and a small cycle study were conducted to verify the validity and reliability of corresponding items. Respondents were asked to evaluate the level to which they have effective practices established in their firms for each of the three dimensions through a total of nine items on a 7-point likert scale.

Dynamic Capabilities (DC) refers to a firm's capacity to (a) to sense and shape opportunities and threats, (b) to seize opportunities, and (c) to maintain competitiveness through enhancing, combining, protecting, and, when necessary, reconfiguring the business enterprise's intangible and tangible assets [39]. Consequently, and following contemporary empirical studies, they are developed as a Type II second-order construct with sensing, seizing, and transforming being the underlying dimensions [40]. Items for each dimension were adopted from prior empirical research that measure the specific notions of dynamic capabilities $[23,28]$. We asked respondents to evaluate their effectiveness in each of the three dimensions/capabilities through a total of nine items on a 7-point likert scale.

Operational Capabilities (OC) are those capabilities through which a firm makes its living in the short term [17]. Operational capabilities have been conceptualized and measured in empirical research as a higher-order construct, consisting of the dimensions of marketing and technological capability $[23,41,42]$. As such, we conceptualize and develop the construct as a Type II second-order construct. A marketing capability refers to the capacity of a firm to link with and serve particular customer groups [43]. Technological capabilities, on the other hand, reflect the organizational capacity to employ technologies to convert inputs into outputs [44]. Respondents were asked to evaluate the effectiveness of their firms in each of the two types of dimensions/capabilities through a total of seven items on a 7-point likert scale.

Competitive Performance (CP) is defined as the degree to which a firm performs better than its key competitors [45]. Respondents were asked to evaluate the relative performance of their firm in terms of profitability, market share, growth, innovativeness, cost leadership, and delivery cycle time [45,46]. Following the argument that competitive performance can be measured by subjective data, we measured the construct as a formative latent variable comprising of seven indicators [41]. Respondents were asked to assess the degree to which they believed that their firm performed better than their main competitors on a 7 point Likert scale $(1$ - Totally disagree 7 - Totally agree).

\section{Analysis and Results}

In order to validate the measurement model and examine the hypothesized relationships, we employed partial least squares (PLS) analysis, a secondgeneration structural equation modeling (SEM) technique. In particular, we used the software package SmartPLS 3 to perform all analyses $[47,48]$.

\subsection{Measurement Model}


Since the model contains both reflective and formative constructs, we used different assessment criteria to evaluate each. For first-order reflective latent constructs we conducted reliability, convergent validity, and discriminant validity tests. Reliability was assessed at both the construct and item level. At the construct level we examined Composite Reliability (CR), and Cronbach Alpha (CA) indices, and established that their values were above the threshold of 0.70 [49]. Indicator reliability was determined by examining if construct-to-item loadings were above the threshold of 0.70 . To establish that convergent validity was achieved, we examined if AVE values were above the lower limit of 0.50 , with the lowest observed value being 0.58 which greatly exceeds this threshold. Discriminant validity was confirmed through three means. The first looked at each constructs AVE square root in order to verify that it is greater than its highest correlation with any other construct (Fornell-Larcker criterion). The second tested if each indicators outer loading was greater that its cross-loadings with other constructs [50]. Recently, Henseler et al. [51] argued that a new criterion called the heterotrait-monotrait ratio (HTMT) is a better assessment indicator of discriminant validity. Values below 0.85 are an indication of sufficient discriminant validity, hence, the obtained results confirm discriminant validity. The results in Table 2 indicate that first-order reflective measures are valid to work with and support the appropriateness of all items as good indicators for their respective constructs [52].

Table 2 Assessment of reliability, convergent and discriminant validity of reflective

\section{constructs}

\begin{tabular}{|c|c|c|c|c|c|c|c|c|c|}
\hline & $\begin{array}{l}\text { STR } \\
\end{array}$ & $\begin{array}{l}\text { PCR } \\
\end{array}$ & RLT & SNS & SZN & TRS & MC & TC & $\mathrm{CP}$ \\
\hline $\begin{array}{l}\text { STR } \\
\end{array}$ & 0.871 & & & & & & & & \\
\hline PCR & 0.531 & 0.705 & & & & & & & \\
\hline RLT & 0.652 & 0.538 & 0.895 & & & & & & \\
\hline SNS & 0.282 & 0.355 & 0.370 & 0.803 & & & & & \\
\hline SZN & 0.453 & 0.447 & 0.501 & 0.485 & 0.880 & & & & \\
\hline TRS & 0.290 & 0.357 & 0.288 & 0.544 & 0.503 & 0.907 & & & \\
\hline MC & 0.114 & 0.147 & 0.248 & 0.571 & 0.263 & 0.328 & 0.700 & & \\
\hline TC & 0.323 & 0.388 & 0.426 & 0.500 & 0.513 & 0.432 & 0.507 & 0.831 & \\
\hline CP & 0.400 & 0.294 & 0.337 & 0.529 & 0.382 & 0.565 & 0.418 & 0.387 & 0.738 \\
\hline Mean & 4.48 & 4.65 & 4.53 & 4.90 & 4.63 & 4.47 & 5.41 & $\begin{array}{l}5.18 \\
\end{array}$ & 4.62 \\
\hline S.D. & 1.23 & 1.41 & 1.35 & 1.49 & 1.36 & 1.39 & 1.25 & 1.26 & 1.41 \\
\hline AVE & 0.758 & 0.587 & 0.800 & 0.658 & 0.833 & 0.808 & 0.594 & 0.714 & 0.593 \\
\hline $\begin{array}{l}\mathrm{CA} \\
\end{array}$ & 0.721 & 0.738 & 0.750 & 0.737 & 0.899 & 0.881 & 0.721 & 0.797 & 0.852 \\
\hline $\begin{array}{ll}\mathrm{CR} \\
\end{array}$ & 0.862 & 0.827 & 0.889 & 0.852 & 0.937 & 0.927 & 0.814 & 0.882 & 0.888 \\
\hline $\begin{array}{l}\text { Note: } \\
\text { TRS } \\
\text { Perfor }\end{array}$ & $\begin{array}{l}\text { - Tran } \\
\text { mance }\end{array}$ & & & & & & & & Seizin \\
\hline
\end{tabular}

For formative first-order constructs we first examined the weights and significance of their association with their respective higher-order constructs. All weights were significant and positive. Next, we examined the extent to which the indicators of formative constructs presented multicollinearity. All values of Variance Inflation Factors (VIF) for firstorder, second-order, and third-order constructs were below the threshold of 3.3 indicating an absence of multicollinearity [53].

\subsection{Structural Model}

The results of the structural model produced by the PLS analysis is summarized in Figure 1, where the explained variance of endogenous variables $\left(R^{2}\right)$ and the standardized path coefficients $(\beta)$ are presented. Significance of estimates (t-statistics) are obtained by performing a bootstrap analysis using 5000 resamples. As depicted in Figure 1, four of the five direct hypotheses were empirically supported. A firms' information governance is found to have a positive and highly significant impact on dynamic capabilities $(\beta=$ $0.556, \mathrm{t}=7.762, \mathrm{p}<0.001)$ but a lesser effect on operational capabilities $(\beta=0.174, \mathrm{t}=2.143, \mathrm{p}<0.05)$. Additionally, dynamic capabilities are found to exert a positive and significant influence on operational capabilities $(\beta=0.576, \mathrm{t}=7.3851, \mathrm{p}<0.001)$. Dynamic capabilities are found to be strongly positively linked with competitive performance gains $(\beta=0.463, \mathrm{t}=5.515, \mathrm{p}<0.001)$, while this relationship is considerably smaller for operational capabilities which demonstrate a marginal, yet significant, effect $(\beta=0.141, \mathrm{t}=2.023, \mathrm{p}<0.05)$. The structural model explains $30.9 \%$ of variance for dynamic capabilities $\left(R^{2}=0.309\right), 39.4 \%$ for operational capabilities $\left(R^{2}=0.394\right)$ and $38.4 \%$ for competitive performance $\left(R^{2}=0.384\right)$. These coefficients of determination represent moderate to substantial predictive power [54]. In addition to examining the $R^{2}$, the model is evaluated by looking at the effect size $f^{2}$. The effect size $f^{2}$ allows us to asses an exogenous constructs contribution to an endogenous latent variables $R^{2}$, and since all direct values are either above the thresholds of 0.15 and 0.35 , we can conclude that the have moderate to high effect sizes.

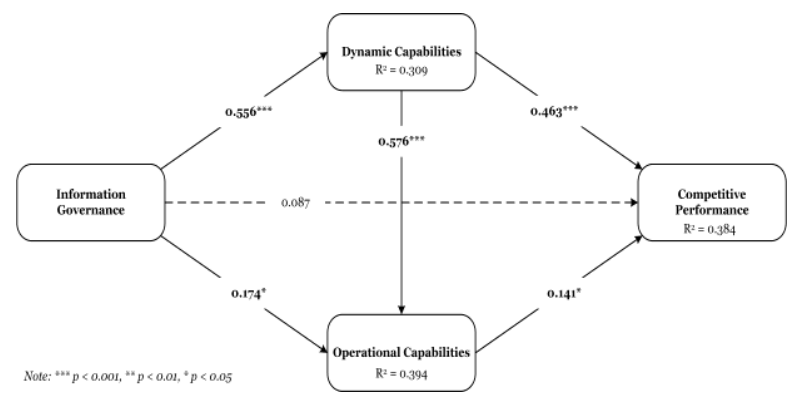

Figure 1 Estimated causal relationships of structural model 
To determine if the impact of information governance on competitive performance is direct or is mediated through dynamic and operational capabilities, a bootstrapping approach is employed, a nonparametric resampling procedure that imposes no assumptions on normality of sampling distribution [54]. Adhering to the guidelines of Hair et al. (2016), we first establish that the mediated paths (IG $\rightarrow \mathrm{DC} \rightarrow$ $\mathrm{CP}$ and $\mathrm{IG} \rightarrow \mathrm{OC} \rightarrow \mathrm{CP})$ are significant. By then including the direct path (IG $\rightarrow \mathrm{CP}$ ) in the model and finding that it is non-significant $(\beta=0.087, \mathrm{t}=0.913, \mathrm{p}>$ 0.05 ) we conclude that full mediation characterized the structural model. In addition, the mediating effect of dynamic capabilities on the relationship between information governance and operational capabilities is established IG $\rightarrow$ DC $\rightarrow$ OC). Significance of indirect effects are calculated by dividing the specific indirect effects by their standard errors. In addition to assessing $R^{2}$ and $f^{2}$ values respectively, the structural model is further validated by examining the $Q^{2}$ predictive relevance of exogenous constructs as well as the effect size $\left(q^{2}\right)$ [55]. By performing a blindfolding procedure, outcomes suggest that dynamic capabilities $\left(Q^{2}=\right.$ $0.169)$, operational capabilities $\left(Q^{2}=0.152\right)$, and competitive performance $\left(Q^{2}=0.182\right)$ have sufficient predictive relevance [54]. Moreover, $q^{2}$ value are in the moderate to high range (above 0.15 and 0.35 respectively), revealing a satisfactory effect size of predictive relevance.

\section{Discussion}

While the hype around big data is continuously growing, the mechanisms and conditions under which it results in business value remain largely unexplored in empirical research. To this end, we build on the notion of information governance as a necessary capacity that firms must cultivate in order to derive any substantial outcomes from their investments. Grounded in the RBV and on past empirical work, we examine the indirect effect that a firms' information governance has on competitive performance. Specifically, we demonstrate that information governance has a positive impact on both a firms' dynamic and operational capabilities. In other words, information governance can facilitate improvements in both the existing mode of operation and also lead to renewed means of competing in market. The complementarities that develop between the two types of capabilities are also confirmed, as is their significance in attaining competitive performance gains.

This study makes an important contribution to big data literature by confirming the value of information governance, as an extension of IT governance, on firm performance [6]. Using survey data from 158
Norwegian high-level executives, this study empirically validated the relationship between a firms' information governance and competitive performance. Specifically, we demonstrated two mechanisms through which these gains are realized. This finding has theoretical relevance since a large number of studies work under the assumption that the capacity to generate data-driven insight is a sufficient condition to attain competitive performance gains. This logic is naturally flawed, since any business value is a result of revamped organizational capabilities that result as a consequence of the newly-discovered knowledge. While this line of thinking is implicitly described in numerous business reports and case studies, it is subject to very limited quantitative empirical research [56].

The current study has some interesting findings that can be applicable in practice. By developing the notion of information governance, this research validates the issue of placing emphasis on a broader picture when it comes to big data. While most attention has been put on gathering data, investing in technological solutions related to hardware and software, and utilizing advanced visualization tools, our findings suggest that without the necessary structural, procedural, and relational practices of information governance, it is most probable that investments will not pay off. Consequently, the underlying dimensions of an information governance can be utilized as a toolbox for chief information officers to develop their firms' governance scheme and focus deployments targeted in strengthening their overall organizational capabilities.

Despite the contributions of the present study it is constrained by a number of limitations that future research should seek to address. As noted already, selfreported data are used to test our research hypotheses. Although considerable efforts were undertaken to confirm data quality, the potential of biases cannot be excluded. The perceptual nature of the data, in conjunction with the use of a single key informant, could suggest that there is bias, and that factual data do not coincide with respondents' perceptions. Although this study relies on top management respondents as key informants, sampling multiple respondents within a single firm would be useful to check for inter-rater validity and to improve internal validity. Furthermore, the study was conducted in a sample of Norwegian firms so it calls for a replication in other countries that have different conditions of conducting business in order to confirm the significance and value of developing an information governance. Finally, although the study examines the importance of information governance on influencing firm organizational capabilities and, effectively, competitive performance, it does not perform a sensitivity analysis 
on contextual factors [57]. Theoretically, it there is support for the claim that information governance and the affected capabilities would vary in significance depending on the dynamism of the environment [58].

\section{Acknowledgements}

This project has received funding from the

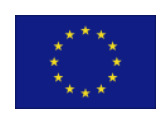

European Union's Horizon 2020 research and innovation programme, under the Marie Sklodowska-Curie grant agreements No 751510 and No 704110

\section{References}

[1] Constantiou, I.D. and J., Kallinikos, "New games, new rules: big data and the changing context of strategy", Journal of Information Technology, 30(1), 2015, pp.44-57.

[2] Gupta, M. and J.F., George, "Toward the development of a big data analytics capability", Information \& Management, 53(8), 2016, pp.1049-1064.

[3] Luftman, J. and T., Ben-Zvi, "Key issues for IT executives 2011: Cautious optimism in uncertain economic times”. MIS Quarterly Executive, 10(4), 2011, pp. 203-212.

[4] De Haes, S. and W., Van Grembergen, “An exploratory study into IT governance implementations and its impact on business/IT alignment", Information Systems Management, 26(2), 2009, pp.123-137.

[5] Chan, Y. E., \& B. H. Reich, "IT alignment: what have we learned?" Journal of Information Technology, 22(4), 2007, 297-315.

[6] Tallon, P.P., R.V. Ramirez, and J.E., Short, "The information artifact in IT governance: toward a theory of information governance", Journal of Management Information Systems, 30(3), 2013, pp.141-178.

[7] Sambamurthy, V. and R.W., Zmud, "Arrangements for information technology governance: A theory of multiple contingencies", MIS Quarterly, 23(2), 1999, pp.261-290.

[8] Weber, K., B, Otto, and H., Österle, "One size does not fit all---a contingency approach to data governance", Journal of Data and Information Quality (JDIQ), 1(1), 2009, pp. 1-27.

[9] Tallon, P.P., "Corporate governance of big data: Perspectives on value, risk, and cost", Computer, 46(6), 2013, pp.32-38.

[10] Mikalef, P., V.A., Framnes, F., Danielsen, J., Krogstie, and D.H. Olsen, "Big Data Analytics Capability: Antecedents and Business Value", In PACIS 2017: 21 ${ }^{\text {st }}$ Pacific Asian Conference on Information Systems. Association for Information Systems. AIS Electronic Library (AISeL).
[11] Sharma, S. and H., Vredenburg, "Proactive corporate environmental strategy and the development of competitively valuable organizational capabilities", Strategic Management Journal, 19(8), 1998, pp.729-753.

[12] Gold, A.H. and A.H.S., Arvind Malhotra, "Knowledge management: An organizational capabilities perspective", Journal of Management Information Systems, 18(1), 2001, pp.185-214.

[13] Winter, S.G., "Understanding dynamic capabilities", Strategic Management Journal, 24(10), 2003, pp.991-995.

[14] Drnevich, P.L. and D.C., Croson, "Information technology and business-level strategy: Toward an integrated theoretical perspective", MIS Quarterly, 37(2), 2013, pp.483509.

[15] Barney, J., "Firm resources and sustained competitive advantage", Journal of Management, 17(1), 1991, pp.99-120.

[16] Amit, R. and P.J., Schoemaker, "Strategic assets and organizational rent", Strategic Management Journal, 14(1), 1993, pp.33-46.

[17] Drnevich, P.L. and A.P., Kriauciunas, "Clarifying the conditions and limits of the contributions of ordinary and dynamic capabilities to relative firm performance", Strategic Management Journal, 32(3), 2011, pp.254-279.

[18] Teece, D.J., G., Pisano, and A., Shuen, "Dynamic capabilities and strategic management", Strategic Management Journal, 18(7), 1997, pp.509-533.

[19] Helfat, C.E. and S.G.,Winter, "Untangling dynamic and operational capabilities: Strategy for the $(\mathrm{N})$ ever-changing world", Strategic Management Journal, 32(11), 2011, pp.1243-1250.

[20] Rasouli, M.R., J.J., Trienekens, R.J. Kusters, and P.W., Grefen, "Information governance requirements in dynamic business networking", Industrial Management \& Data Systems, 116(7), 2016, pp.1356-1379.

[21] Kathuria, A., T.J.V., Saldanha, J. Khuntia, and M.G., Andrade Rojas, "How Information Management Capability Affects Innovation Capability and Firm Performance under Turbulence: Evidence from India", In ICIS 2016: 37th International Conference on Information Systems. Association for Information Systems. AIS Electronic Library (AISeL).

[22] Murdoch, T.B. and A.S., Detsky, "The inevitable application of big data to health care", Jama, 309(13), 2013, pp.1351-1352.

[23] Agarwal, R. and W., Selen, "Dynamic capability building in service value networks for achieving service innovation", Decision Sciences, 40(3), 2009, pp.431-475. 
[24] Mikalef, P. and A., Pateli, "Information technologyenabled dynamic capabilities and their indirect effect on competitive performance: Findings from PLS-SEM and fsQCA”, Journal of Business Research, 70, 2017, pp.1-16.

[25] Makadok, R., "Toward a synthesis of the resource-based and dynamic-capability views of rent creation", Strategic Management Journal, 22(5), 2001, pp.387-401.

[26] Tallon, P.P., "Inside the adaptive enterprise: an information technology capabilities perspective on business process agility", Information Technology and Management, 9(1), 2008, pp.21-36.

[27] Karna, A., A., Richter, and E., Riesenkampff, "Revisiting the role of the environment in the capabilitiesfinancial performance relationship: A meta-analysis", Strategic Management Journal, 37(6), 2016, pp.1154-1173.

[28] Protogerou, A., Y. Caloghirou, and S., Lioukas, "Dynamic capabilities and their indirect impact on firm performance", Industrial and Corporate Change, 21(3), 2012, pp.615-647.

[29] Hooley, G.J., G.E., Greenley, J.W. Cadogan, and J., Fahy, "The performance impact of marketing resources", Journal of Business Research, 58(1), 2015, pp.18-27.

[30] Eisenhardt, K.M. and J.A., Martin, "Dynamic capabilities: what are they?", Strategic Management Journal, 21(10/11), 2000, pp.1105-1121.

[31] Pavlou, P.A. and O.A., El Sawy, "From IT leveraging competence to competitive advantage in turbulent environments: The case of new product development", Information Systems Research, 17(3), 2006, pp.198-227.

[32] Zahra, S.A., H.J. Sapienza, and P., Davidsson, "Entrepreneurship and dynamic capabilities: A review, model and research agenda", Journal of Management Studies, 43(4), 2006, pp.917-955.

[33] Kumar, N., L.W. Stern, and J.C., Anderson, "Conducting interorganizational research using key informants", Academy of Management Journal, 36(6), 1993, pp.1633-1651.

[34] Capron, L. and W., Mitchell, "Selection capability: How capability gaps and internal social frictions affect internal and external strategic renewal", Organization Science, 20(2), 2009, pp.294-312.

[35] Sax, L.J., S.K., Gilmartin, and A.N., Bryant, “Assessing response rates and nonresponse bias in web and paper surveys", Research in Higher Education, 44(4), 2003, pp.409-432.

[36] Chang, S.J., A. Van Witteloostuijn, and L., Eden, "From the editors: Common method variance in international business research", Journal of International Business Studies, 41(2), 2010, pp.178-184.
[37] Fuller, C.M., M.J., Simmering, G., Atinc, Y. Atinc, and B.J., Babin, "Common methods variance detection in business research", Journal of Business Research, 69(8), 2016, pp.3192-3198.

[38] Peterson, R., "Crafting information technology governance”, Information Systems Management, 21(4), 2004, pp.7-22.

[39] Teece, D.J., "Explicating dynamic capabilities: the nature and microfoundations of (sustainable) enterprise performance", Strategic Management Journal, 28(13), 2007, pp.1319-1350.

[40] Wilden, R., S.P., Gudergan, B.B. Nielsen, and I., Lings, "Dynamic capabilities and performance: strategy, structure and environment", Long Range Planning, 46(1), 2013, pp.7296.

[41] Spanos, Y.E. and S., Lioukas, "An examination into the causal logic of rent generation: contrasting Porter's competitive strategy framework and the resource-based perspective", Strategic Management Journal, 22(10), 2001, pp.907-934.

[42] Wilden, R. and S.P., Gudergan, "The impact of dynamic capabilities on operational marketing and technological capabilities: investigating the role of environmental turbulence", Journal of the Academy of Marketing Science, 43(2), 2015, pp.181-199.

[43] Danneels, E., "Organizational antecedents of second-order competences", Strategic Management Journal, 29(5), 2008, pp.519-543.

[44] Afuah, A., "Mapping technological capabilities into product markets and competitive advantage: the case of cholesterol drugs", Strategic Management Journal, 23(2), 2002, pp.171-179.

[45] Rai, A. and X., Tang, "Leveraging IT capabilities and competitive process capabilities for the management of interorganizational relationship portfolios", Information Systems Research, 21(3), 2010, pp.516-542.

[46] Liu, H., W., Ke, K.K. Wei, and Z., Hua, "The impact of IT capabilities on firm performance: The mediating roles of absorptive capacity and supply chain agility", Decision Support Systems, 54(3), 2013, pp.1452-1462.

[47] Ringle, C.M., S. Wende, and J.M., Becker, "SmartPLS 3. Boenningstedt: SmartPLS GmbH”, 2015.

[48] Hair, J.F., C.M. Ringle, and M., Sarstedt, "PLS-SEM: Indeed a silver bullet", Journal of Marketing theory and Practice, 19(2), 2011, pp.139-152.

[49] Nunnally, J. C. Psychometric Theory 3E. Tata McGrawHill Education, 1978. 
[50] Farrell, A.M., "Insufficient discriminant validity: A comment on Bove, Pervan, Beatty, and Shiu (2009)", Journal of Business Research, 63(3), 2010, pp.324-327.

[51] Henseler, J., C.M. Ringle, and M., Sarstedt, "A new criterion for assessing discriminant validity in variance-based structural equation modeling", Journal of the Academy of Marketing Science, 43(1), 2015, pp.115-135.

[52] Ruiz, D.M., D.D., Gremler, J.H. Washburn, and G.C., Carrión, "Service value revisited: Specifying a higher-order, formative measure", Journal of Business Research, 61(12), 2008, pp.1278-1291.

[53] Petter, S., D. Straub, and A., Rai, "Specifying formative constructs in information systems research", MIS Quarterly, 31(4), 2007, pp.623-656.

[54] Hair Jr, J.F. and Hult, G.T.M., 2016. A primer on partial least squares structural equation modeling (PLS-SEM). Sage Publications.

[55] Woodside, A.G., "Moving beyond multiple regression analysis to algorithms: Calling for adoption of a paradigm shift from symmetric to asymmetric thinking in data analysis and crafting theory", Journal of Business Research, 66(4), 2013, pp. 463-472.

[56] Mikalef, P., I.O., Pappas, J., Krogstie, and M. Giannakos, M. "Big data analytics capabilities: a systematic literature review and research agenda", Information Systems and e-Business Management, pp.1-32.

[57] van de Wetering, R., P., Mikalef, and R. Helms, "Driving organizational sustainability-oriented innovation capabilities: a complex adaptive systems perspective", Current Opinion in Environmental Sustainability, 28, 2017, pp. 71-79.

[58] Mikalef, P., I.O., Pappas, M.N., Giannakos, J., Krogstie, and G. Lekakos, "Big Data and Strategy: A research Framework", In MCIS 2016: $10^{\text {th }}$ Mediterranean Conference on Information Systems. Association for Information Systems. AIS Electronic Library (AISeL).

\section{Appendix A. Survey Instrument}

\begin{tabular}{|l|}
\hline Structural Practices \\
\hline In our organization, we \\
\hline $\begin{array}{l}\text { STR1. have identified key IT and non-IT decision makers to } \\
\text { have the responsibility regarding data ownership, value } \\
\text { analysis and cost management. }\end{array}$ \\
\hline $\begin{array}{l}\text { STR2. use steering committees to oversee and assess data } \\
\text { values and costs }\end{array}$ \\
\hline Procedural Practices \\
\hline $\begin{array}{l}\text { In our organization, we have controlled practices regarding } \\
\text { data management in terms of }\end{array}$ \\
\hline PCR1. setting retention policies (e.g. time to live) of data \\
\hline PCR2. backup routines \\
\hline PCR3. establishing/monitoring access (e.g. user access) to \\
\hline
\end{tabular}

\begin{tabular}{|c|}
\hline data \\
\hline PCR4. classifying data according to value \\
\hline PCR5. monitoring costs versus value of data \\
\hline Relational Practices \\
\hline In our organization, we \\
\hline $\begin{array}{l}\text { RLT1. educate users and non-IT managers regarding storage } \\
\text { utilization and costs }\end{array}$ \\
\hline $\begin{array}{lccc}\text { RLT2. develop communications } & \text { regarding } & \text { policy } \\
\text { effectiveness and user needs } & & & \\
\end{array}$ \\
\hline Sensing Capability \\
\hline $\begin{array}{l}\text { SNS1. We frequently scan the environment to identify new } \\
\text { business opportunities }\end{array}$ \\
\hline $\begin{array}{l}\text { SNS2. We often review our product development efforts to } \\
\text { ensure they are in line with what the customers want }\end{array}$ \\
\hline $\begin{array}{l}\text { SNS3. We use established processes to identify target market } \\
\text { segments, changing customer needs and customer innovation }\end{array}$ \\
\hline Seizing Capability \\
\hline $\begin{array}{l}\text { SZN1. When opportunities or threats are sensed, our } \\
\text { organization has effective routines for drafting various } \\
\text { potential solutions }\end{array}$ \\
\hline $\begin{array}{l}\text { SZN2. When opportunities or threats are sensed, our } \\
\text { organization has effective routines for evaluating and } \\
\text { selecting potential solutions }\end{array}$ \\
\hline $\begin{array}{l}\text { SZN3. When opportunities or threats are sensed, our } \\
\text { organization has effective routines for starting on a detailed } \\
\text { plan to carry out a potential solution }\end{array}$ \\
\hline Transforming Capability \\
\hline $\begin{array}{l}\text { TRS1. Our organization can successfully create new or } \\
\text { substantially changed ways of achieving our targets and } \\
\text { objectives }\end{array}$ \\
\hline $\begin{array}{l}\text { TRS2. Our organization can successfully adjust our business } \\
\text { processes in response to shifts in our business priorities }\end{array}$ \\
\hline $\begin{array}{l}\text { TRS3. Our organization can successfully reconfigure our } \\
\text { business processes in order to come up with new productive } \\
\text { assets }\end{array}$ \\
\hline Marketing Capability \\
\hline $\begin{array}{l}\text { Our organization has excellent capabilities when it comes } \\
\text { to }\end{array}$ \\
\hline MC1. Market knowledge \\
\hline MC2. Control and access to distribution channels \\
\hline MC3. Advantageous relationships with customers \\
\hline MC4. Established customer base \\
\hline Technological Capability \\
\hline $\begin{array}{l}\text { Our organization has excellent capabilities when it comes } \\
\text { to }\end{array}$ \\
\hline TC1. Efficient and effective production/services \\
\hline TC2. Economies of scales and technical expertise \\
\hline TC3. Technological capabilities and equipment \\
\hline Competitive Performance \\
\hline $\begin{array}{l}\text { We perform much better than our main competitors in terms } \\
\text { of: }\end{array}$ \\
\hline CP1. profitability \\
\hline $\mathrm{CP} 2$ return on investment $(\mathrm{ROI})$ \\
\hline CP3. growth in market share \\
\hline CP4. sales growth \\
\hline CP5. rapid response to market demand \\
\hline CP6. in reducing operating costs \\
\hline CP7. increasing customer satisfaction \\
\hline
\end{tabular}

